\title{
193 nm Resists for Deep Sub-Wavelength Applications
}

\author{
R. Dammel, M. Cook, A. Klauck-Jacobs, T. Kudo*, S. Mehtsun, \\ J. Oberlander, M. Padmanaban, and D.L. Rahman, \\ AZ Electronic Materials, Clariant Corporation, 70 Meister Avenue, Somerville, NJ 08876, USA \\ * AZ Electronic Materials, Clariant Japan K.K., Chihama, Daito-cho, Ogasa-sun, Shizuoka 437-14, Japan
}

\begin{abstract}
Among the chemistries/polymers reported for the $193 \mathrm{~nm}$ photoresist applications, methacrylate copolymers consisting of 2-methyl-2-adamantane methacrylate (2-MadMA) and mevalonic lactone methacrylate (MLMA) and cycloolefin polymers derived from derivatives of norbormene have shown promising results. We have studied the lithographic properties of these two different promising chemistries. Both systems offer linear resolutions down to $130 \mathrm{~nm}$ dense lines using conventional 193 $\mathrm{nm}$ illumination and high sensitivity at standard developer conditions. The etch rates of the methacrylate and cycloolefin based resists for polysilicon were found to be 1.4 and 1.3 times higher than that of novolak resist. Calculation of the normalized image log-slope (NILS) for both resist types shows that they can still resolve aerial images with a NILS of about 1.0, which is also confirmed by their $248 \mathrm{~nm}$ performance. The potential of $193 \mathrm{~nm}$ lithography is estimated at $110 \mathrm{~nm}$ dense line resolution if resists can be improved to match the performance of dense line resolution if resists can be improved to match the performance of the best current $248 \mathrm{~nm}$ resists which can resolve NILS values of about 0.7
\end{abstract}

Keywords: $193 \mathrm{~nm}$ resists, methacrylate copolymers, 2-methyl-2-adamantane methacrylate, mevalonic lactone methacrylate, polysilicon, novolak resist

\section{Introduction}

The introduction of $193 \mathrm{~nm}$ lithography into manufacturing is seen to occur at the earliest for the $130 \mathrm{~nm}$ technology node. This makes 193 $\mathrm{nm}$ lithography the first lithographic technology to be introduced at $\mathrm{CD}$ design rules that are substantially smaller than the wavelength of the imaging light. At the introduction of i-line lithography, the CD's printed were about 1.5 times larger than the $365 \mathrm{~nm}$ wavelength, while at the time of transition to mainstream $248 \mathrm{~nm}$ DUV lithography, the ratio had already shrunk to unity. If $193 \mathrm{~nm}$ lithography is introduced for the $130 \mathrm{~nm}$ technology node, the ratio will be as low as $67 \%$ of the imaging wavelength. Such deep sub-wavelength lithography will put special demands on photoresists, and it is presently not clear if $193 \mathrm{~nm}$ resist development can be pushed to a performance that will allow the industry to avoid the widespread use of optical enhancements.

The task facing the resist chemists is not made easier by the constraints placed upon them by the nature of the problem. For any optical lithography beyond i-line, the design of resist systems is primarily determined by the polymer absorbance. For $248 \mathrm{~nm}$ lithography, the high absorbance of novolaks necessitated a switch to polyhydroxystyrene as a base polymer; since PHS does not show the same dissolution inhibition phenomena as novolak, functional group deprotection and chemical amplification had to be introduced. Similarly, for $193 \mathrm{~nm}$ lithography, the high absorbance of double 
bonds has required the development of new wholly aliphatic polymers using carboxylic acid groups as a substitute for the acidity of the phenolic group. For $157 \mathrm{~nm}$ lithography, a technology which has recently seen a large boost in interest as a means of further extending optical lithography, even carboxylic acid groups are too absorbing, and current development concepts focus on fluoroalcohols or siloxanes as possible base resins.

The design of polymers for $193 \mathrm{~nm}$ photoresist applications requires the delicate act of balancing the hydrophilic/hydrophobic nature of the polymer with the introduction of etch resistant and adhesion promoting units. Pioneering work at IBM and Fujitsu showed the feasibility of imaging with aliphatic polymers but also the need to embody highly annelated carbon rings to provide dry etch resistance. The annelated structures in these polymers can be introduced either in the main chain or in the side chains. For instance, researchers at $\mathrm{NEC}^{1}$ and Fujitsu $^{2-3}$ have introduced tricyclododecyl and adamantane groups in the side chains of methacrylate type polymers, respectively. More recently, systems have been reported in which the annelated carbon rings are introduced in the main chain ${ }^{4-6}$ through cycloolefin monomers. From a synthesis point of view, both systems have several drawbacks. In the case of the methacrylate systems, making the polymer is easy but some of the annelated monomers are difficult to purify and are expensive unless produced in large quantities. The cycloolefin type monomers (usually norbornene and derivatives) are easily prepared, usually in quantitative yields, by the Diels-Alder reaction using cyclopentadiene and acrylate monomers. Free radical polymerization is, however, only possible by alternating copolymerization with electron deficient monomers such as maleic anhydride, a reaction for which good yields and reproducibility are often critical. Direct vinyl addition polymerization can be effected by means of metal catalysis. All of the systems that are presently being developed for commercial use fall into one of these three classes, or are hybrids thereof.

It has been pointed out by several groups that the performance of $193 \mathrm{~nm}$ polymers is yet inferior to that of $248 \mathrm{~nm}$ resist materials. A direct performance comparison is easily carried out since the $193 \mathrm{~nm}$ polymers are also transparent at $248 \mathrm{~nm}$, and because the formulations commonly contain the same onium salt sensitizers used for $248 \mathrm{~nm}$ resists. In this paper, we use the normalized image log-slope (NILS) as a measure to determine the imaging capability of our $193 \mathrm{~nm}$ systems, and to compare them to that of state-of-the-art $248 \mathrm{~nm}$ systems.

In particular, we have studied the synthesis and lithographic properties of resist formulations based on a copolymer of 2methyladamantylmethacrylate (2-MAdMA) with mevalonic lactone methacrylate (MLMA), and of a number of polymers derived from norbornene carboxylates and maleic anhydride.

\section{Experimental}

\subsection{Synthesis of 2-MAdMA, MLMA and their copolymers}

As shown in Scheme 1, 2-MAdMA was synthesized by the reaction of methacryloyl chloride and 2-methyladamantanol in presence of triethylamine base at $-40{ }^{\circ} \mathrm{C}$. It was preferentially purified by distillation under reduced pressure $\left(105^{\circ} \mathrm{C} /<1 \mathrm{~mm} \mathrm{Hg}\right)$. MLMA was prepared by reacting methacrylol chloride and mevalonic lactone. This monomer can also be purified either by distillation under reduced pressure, however, great care is necessary during purification of this monomer as it is prone to elimination reaction under the reaction 
conditions. Polymerizations were carried out in THF using AIBN initiator at $70^{\circ} \mathrm{C}$ for over 5 hours under nitrogen atmosphere. Typical polymerization yields were above $65 \%$.

\subsection{Polymer characterization}

Polymer structures were confirmed by both IR and NMR. Molecular weights were determined on gel-permeation chromatography (GPC) using polystyrene standard. Thermal studies were conducted by thermogravimetric analysis (TGA), differential scanning calorimetry (DSC) or modulated temperature differential scanning calorimetry (MT/DSC) as described in the literature. $^{7}$

\subsubsection{Resist formulations, exposures and etch rate measurements}

The $\mathrm{AZ}^{\circledR} \mathrm{EXP} \mathrm{AX}^{\mathrm{TM}} 1000 \mathrm{P}$ resist is based on a close to 1:1 MAdMA/MLMA copolymer. This formulation was chosen for commercial sampling activities and is available in gallon quantities. Resist formulations were made in ethyl lactate solution of the respective polymer, onium type photoacid generator (about $2 \mathrm{w} / \mathrm{w} \%$ solids), and a small amount of base additive was included. Exposures were carried out on an ISI
0.60 NA mini stepper at International SEMATECH, Austin/Texas. Resists were coated either on bare silicon wafers or on wafers coated with $39 \mathrm{~nm}$ of AZ EXP ArF-1 $193 \mathrm{~nm}$ bottom coat (baked at $175^{\circ} \mathrm{C}$ for 60 seconds) on a FSI Polaris coating track. The wafers were soft baked at $115^{\circ} \mathrm{C}$ for 60 seconds on a hot plate. Resist thickness was determined to be $0.451 \mu \mathrm{m}$ on a Prometrix film thickness measurement tool. After exposure, the wafers were post exposure baked at $110^{\circ} \mathrm{C}$ for 60 seconds and developed in a $60 \mathrm{sec}$ spray/puddle process with LD26W (2.38 wt \% aqueous TMAH) developer at $23^{\circ} \mathrm{C}$ using a short pre-wet cycle. The cross-sections of the developed patterns were observed by scanning electron microscopy. The blanket polysilicon etch rate measurements were done on a LAM 9400 machine at $300 \mathrm{~W} / 150 \mathrm{~W} / 10 \mathrm{mT} / 50 \mathrm{sccm} \mathrm{Cl}_{2} / 150$ sccm $\mathrm{HBr} / 65^{\circ} \mathrm{C}$.

\section{Performance of $193 \mathrm{~nm}$ Resists}

\subsection{Lithographic Properties of $\mathbf{A Z}{ }^{\mathbb{E}} \mathbf{E X P}$ AX-1000P Resist}

On the SEMATECH ISI $193 \mathrm{~nm}$ ministepper system $(\mathrm{NA}=0.60, \sigma=0.70)$, the $\mathrm{AZ}^{\circledR} \mathrm{EXP}$ $\mathrm{AX}^{\mathrm{TM}} 1000 \mathrm{P}$ resist shows high resolution up to

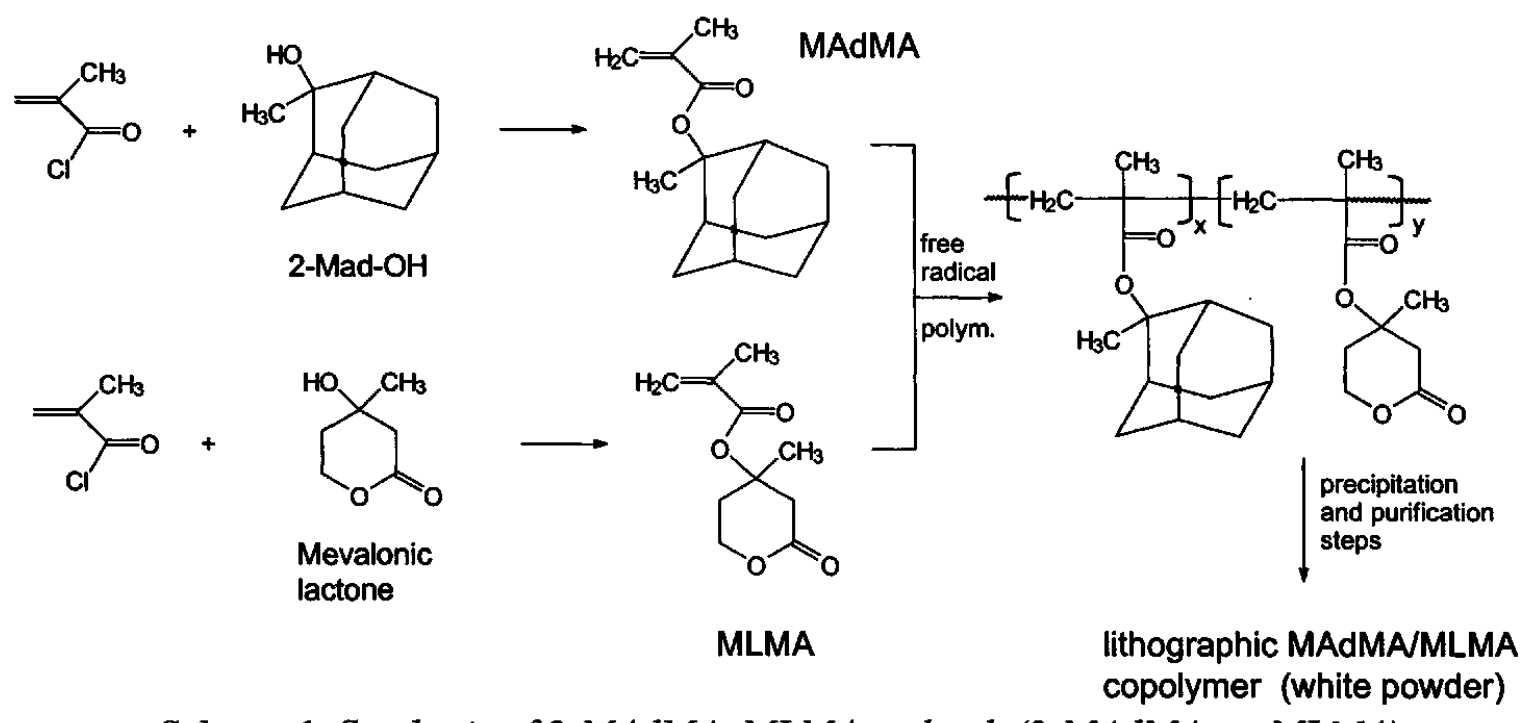

Scheme 1. Synthesis of 2-MAdMA, MLMA and poly(2-MAdMA-co-MLMA) 

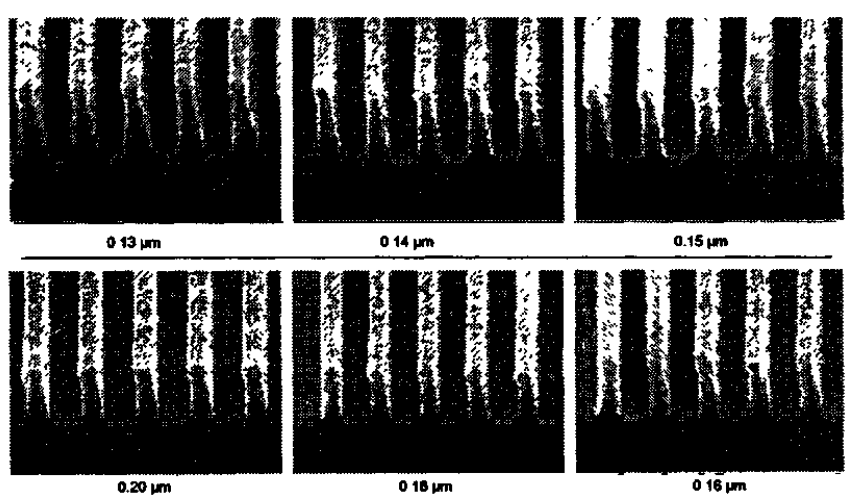

Figure 1 (right): Dense line performance of $A Z^{\circledR} E X P A X^{\mathrm{TM}} 1000 P$ (binary mask, standard illumination; $0.451 \mu \mathrm{m}$ film thickness $\left(E_{\max }\right), 17$ $\mathrm{mJ} / \mathrm{cm}^{2}$ )
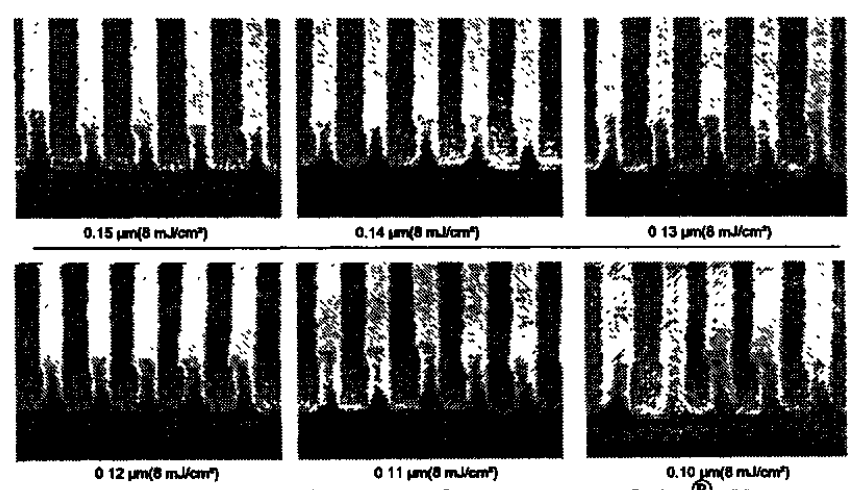

Figure 3. Dense line performance of $A Z^{B} E X P$ $A X^{\mathrm{TM}} 1000 P$ using a strong phase shift mask

$(N A=0.60, \sigma=0.30)$

$0.13 \mu \mathrm{m}$ (Figure 1) for dense lines with a conventional chrome-on-glass mask. The depth of focus for $130 \mathrm{~nm}$ dense lines is about 0.40 $\mu \mathrm{m}$, that for $150 \mathrm{~nm}$ dense lines about $0.50 \mu \mathrm{m}$ (Figure 2). The sensitivity of the resist (dose to print) under these conditions is $13 \mathrm{~mJ} / \mathrm{cm}^{2}$ on a bottom A.R.C. Using a strong phase shift mask and $\sigma=0.30$, one obtains dense line resolution
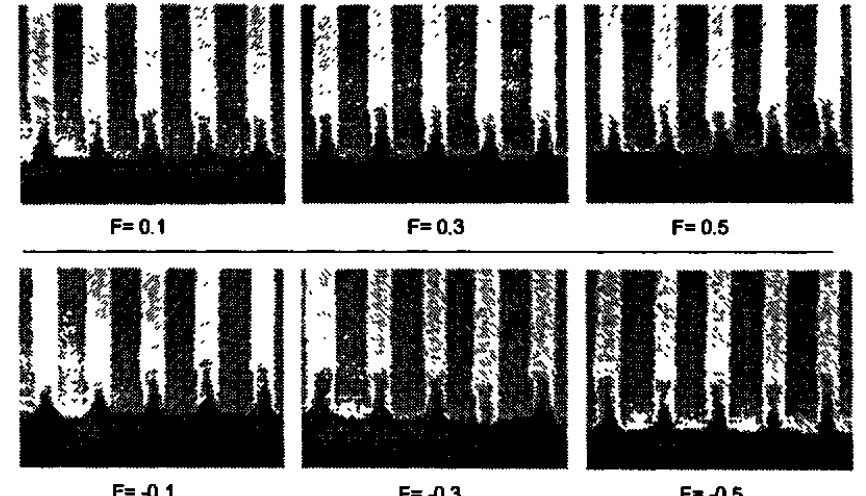

Figure 4. Depth of focus for $0.15 \mu \mathrm{m} \mathrm{L/S} \mathrm{of}$ $A Z^{\circledR} E X P A X^{\mathrm{TM}} 1000 P$ using phase shift mask

down to $0.10 \mu \mathrm{m}$ (Fig. 3), which was the smallest dense feature on the mask, and a depth of focus of $1.0 \mu \mathrm{m}$ for the $0.15 \mu \mathrm{m}$ dense lines (Fig. 4). One of the resist's characteristic features is a low iso-dense line bias, which is believed to be reduced below the intrinsic bias of the aerial image by a near-optimal diffusivity of the catalytic acid. The resist also shows good performance for contact hole patterns (Fig. 5), and has high thermal stability of up to $135^{\circ} \mathrm{C}$ (Fig 6). The polysilicon etch rate using $\mathrm{Cl}_{2} / \mathrm{HBr}$ etchant was determined to be 1.4 times to that of novolak. One issue that is still being addressed with this type of formulation is the adhesion at high aspect ratios on silicon substrates which currently limits resolution to 0.15 to $0.14 \mu \mathrm{m}$ in about half-micron thick films.

When investigating the thermal flow stability of developed $\quad \mathrm{AZ}^{\mathbb{B}} \mathrm{EXP} \quad \mathrm{AX}^{\mathrm{TM}} 1000 \mathrm{P}$ resist structures, no flow of the resist features was observed for heating temperatures as high as

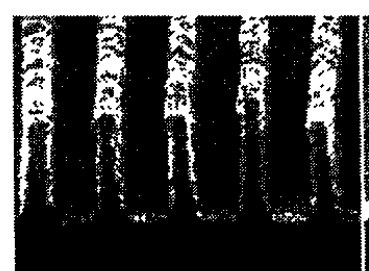

$-0.20 \mu \mathrm{m}$

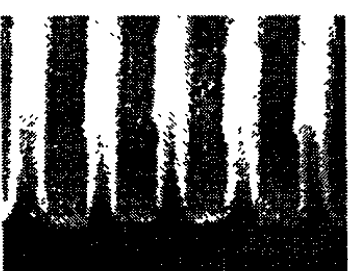

$-0.10 \mu \mathrm{m}$

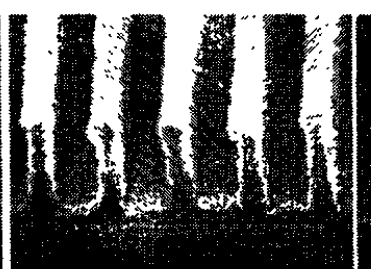

best focus

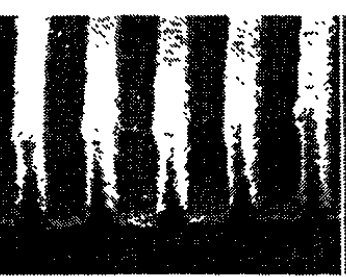

$+0.10 \mu m$

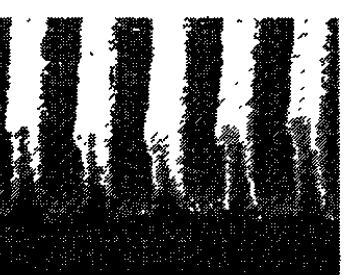

$+0.20 \mu \mathrm{m}$

Figure 2: Depth of focus for $0.15 \mu \mathrm{m} L / S$ in $A Z^{\circledR} E X P A X^{\mathrm{TM}} 1000 P$ resist (binary mask, standard illumination). 


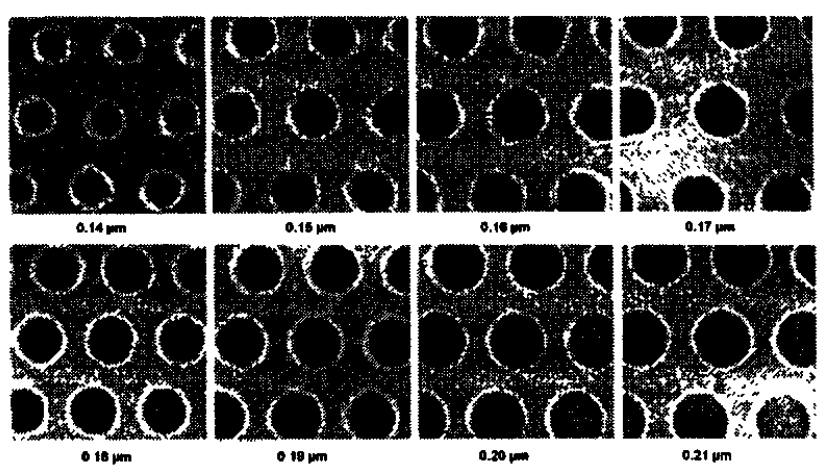

Figure 5: Dense contact hole performance of $A Z^{\circledR} E X P A X-1000 P$ (binary mask, $26 \mathrm{~mJ} / \mathrm{cm}^{2}$ )

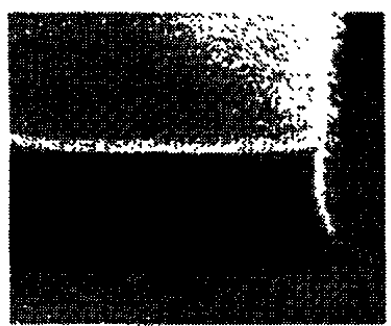

No Bake

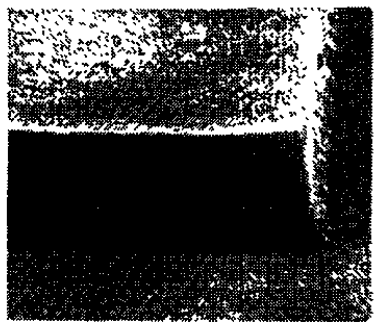

$135^{\circ} \mathrm{C}$
Figure 6. Thermal flow stability of $A Z^{\circledR} E X P$ $A X^{\mathrm{TM}} 1000 P$

$135{ }^{\circ} \mathrm{C}$ (Fig. 6). The observed thermal flow temperature was thus higher than the $\mathrm{T}_{\mathrm{g}}$ of 105 ${ }^{\circ} \mathrm{C}$ previously quoted in the literature. ${ }^{3}$ It was therefore concluded that due to the difficulty of the experiment, the earlier measurement must have been in error, and that the $T_{g}$ of the photoresist must substantially exceed that temperature.

The determination of glass transition temperatures of stiff polymers such as those used in today's $193 \mathrm{~nm}$ resist systems is very difficult with standard DSC methods. Acrylic backbones with large pendant side groups exhibit only small heat capacity changes during the glass transition, which moreover may stretch out over a larger than normal temperature range. Very often, the glass transition temperatures of these polymers cannot be determined due to a lack of sensitivity of standard Differential Scanning
Calorimetry (DSC), or, in some cases, because the transition is convoluted with chemical changes in the polymer or photoresist. We have recently reported ${ }^{7}$ on the use of Modulated Temperature Differential Scanning Calorimetry (MT-DSC) and other methods to overcome these difficulties. As a result of these studies, it was found that the glass transition temperature of the 2-MAdMA/MLMA 1:1 copolymer was about $155^{\circ} \mathrm{C}$, and that the glass transition temperature of $\mathrm{AZ}^{\circledR} \mathrm{EXP} \mathrm{AX}^{\mathrm{TM}} 1000 \mathrm{P}$ is as high as $150^{\circ} \mathrm{C}$ (Figs. 7 and 8 ).

While these results are in full confirmation of the thermal flow experiment of Fig. 6, they also indicate that contrary to what had been previously thought, the $\mathrm{AZ}^{\circledR} \mathrm{EXP} \mathrm{AX}^{\mathrm{TM}} 1000 \mathrm{P}$
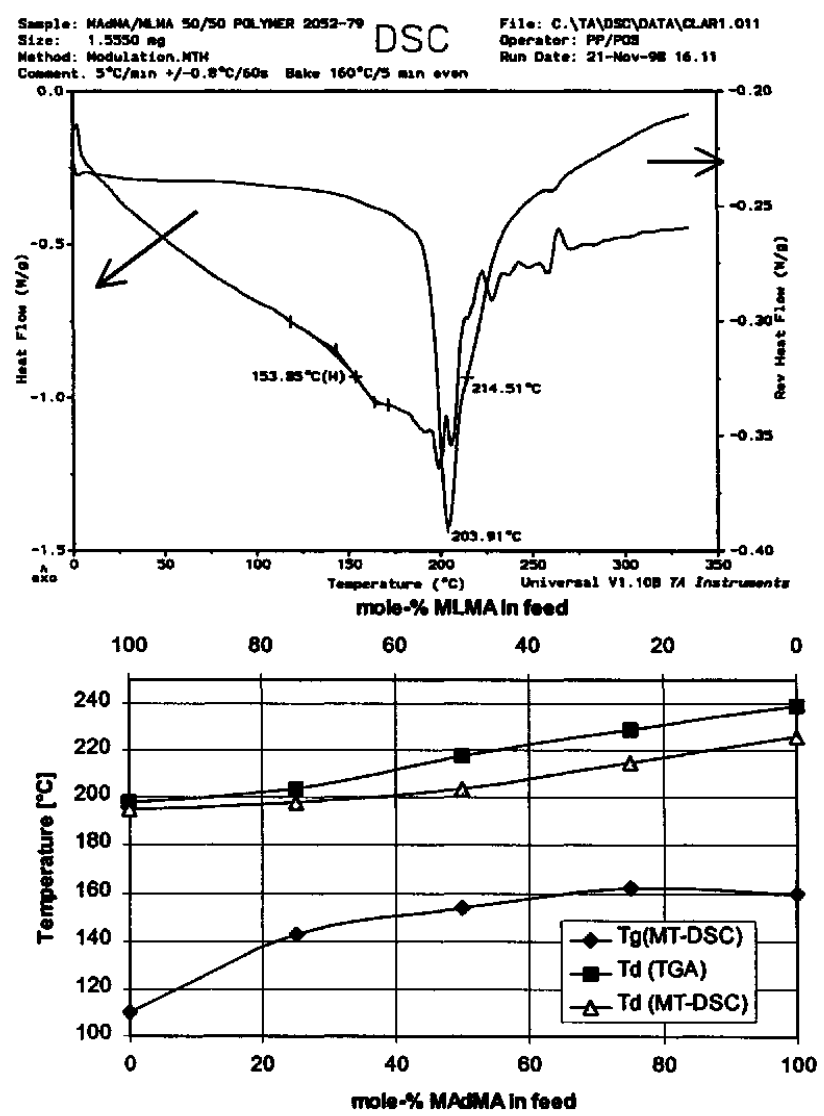

Fig. 7: Glass transition and decomposition temperatures for 2-MAdMA/MLMA copolymers. ${ }^{7}$ 

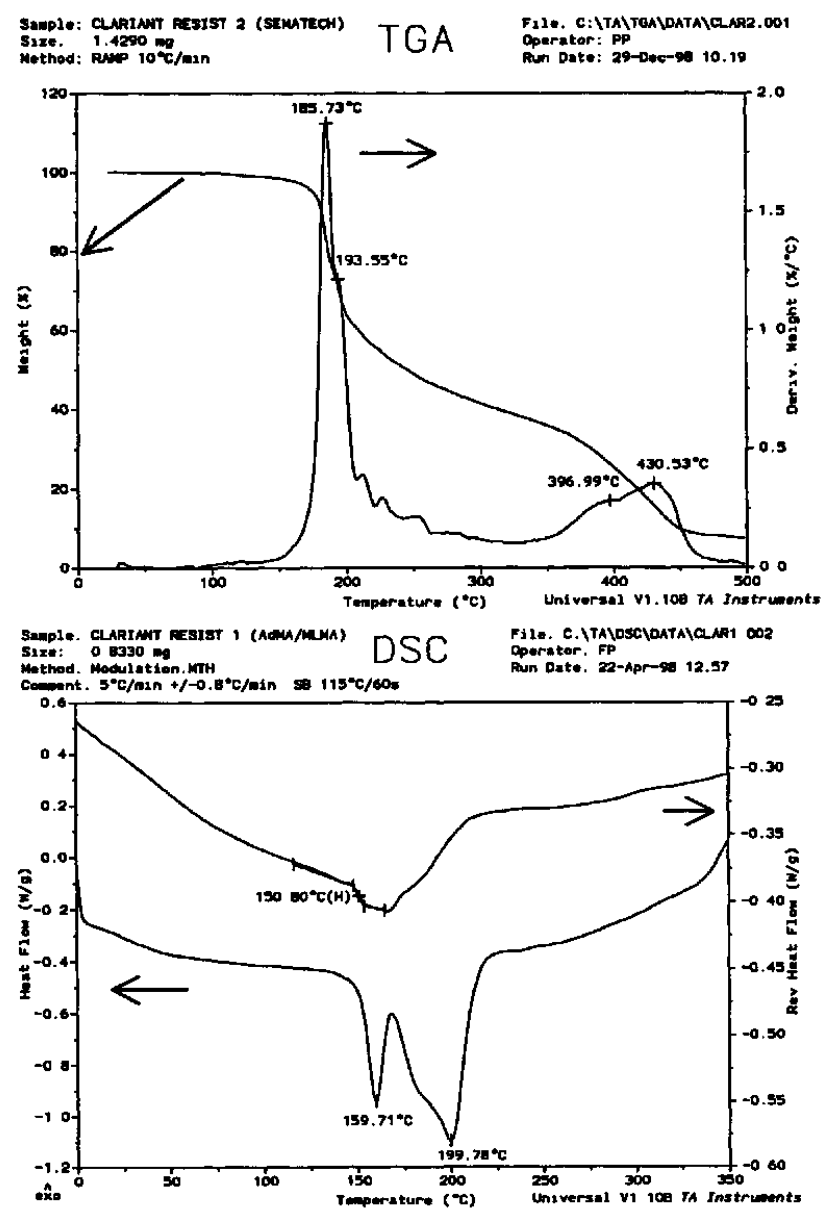

Fig. 8: Glass transition and decomposition temperatures of $A Z^{\circledR} E X P A X^{\mathrm{TM}} 1000 P$ resist. $^{7}$

resist is not annealed under the present softbake conditions $\left(115^{\circ} \mathrm{C}, 1 \mathrm{~min}\right)$. As a result of this, one would expect to find sensitivity of the resist to atmospheric contamination. Delay time studies show that this is indeed the case: after 10 min in a filtered environment (ca. 3 - 5 ppb base contamination level), the resist begins to show signs of T-topping, which has become severe after 30 min (Fig. 9, A); after 1 hour, the resist fails completely.

As one of the approaches we are pursuing to improve the delay time stability of this type of resist, we have investigated the admixture of an additive based on a $193 \mathrm{~nm}$-adapted version of

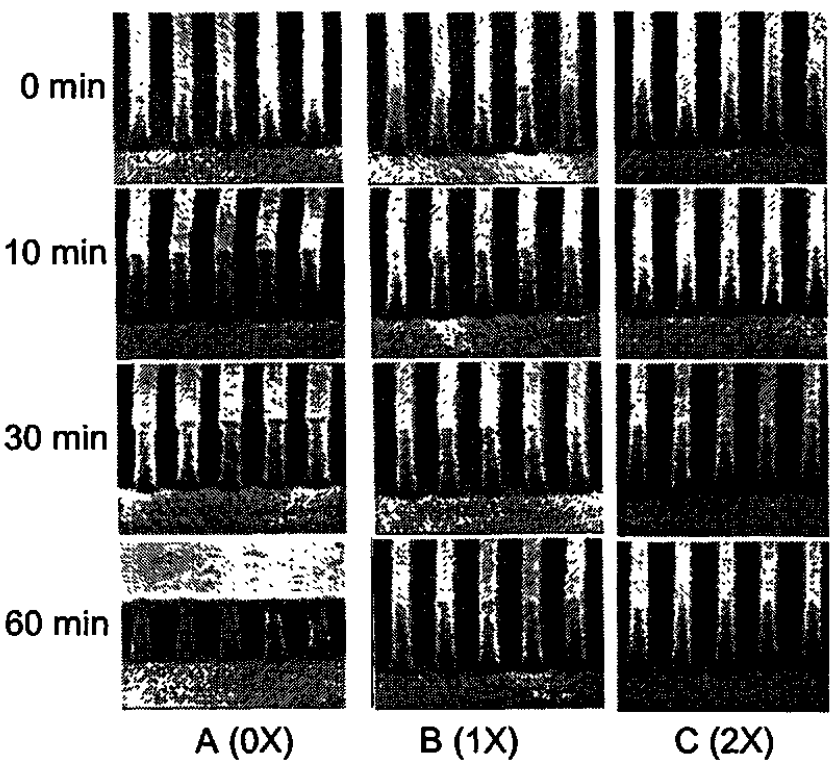

Fig. 9 (right): Delay time stability of 2MAdMA/MLMA-based resist with $193 \mathrm{~nm}$ version of photobase additive for $140 \mathrm{~nm}$ dense lines. A) Additive level $0 X\left(12 \mathrm{~mJ} / \mathrm{cm}^{2}\right)=A Z^{\circledR}$ EXP $A X^{\mathrm{TM}} 1000 P$ (contains non-photobase additive), B) additive level $\left.1 X\left(14 \mathrm{~mJ} / \mathrm{cm}^{2}\right), C\right)$ additive level $2 X\left(28 \mathrm{~mJ} / \mathrm{cm}^{2}\right)$. Filtered environment with 3-5 ppb airborne base. Except for the SEM in the lower left corner, all experiments were carried out on the same day.

AZ's patented photobase technology. Three levels of additive were studied: at the $1 \mathrm{X}$ level, the photospeed was approximately equal to unmodified $\mathrm{AZ}^{\circledR}$ EXP AXTM1000P $\left(14 \mathrm{~mJ} / \mathrm{cm}^{2}\right)$, at the $2 \mathrm{X}$ level, it had approximately doubled $\left(28 \mathrm{~mJ} / \mathrm{cm}^{2}\right)$, and at the $3 \mathrm{X}$ level, the photospeed had become too low for a practically useful resist $\left(>45 \mathrm{~mJ} / \mathrm{cm}^{2}\right.$ as extrapolated from the dose-to-clear of $18 \mathrm{~mJ} / \mathrm{cm}^{2}$ ). Delay time studies for the $1 \mathrm{X}$ and $2 \mathrm{X}$ levels showed that there was no T-top formation for a period of up to 1 hour in filtered atmosphere (Fig. 9: B, C). The formulation at the $1 \mathrm{X}$ level was used as the basis for the new, delay time stable $A Z^{\circledR} \mathrm{EXP}$ $\mathrm{AX}^{\mathrm{TM}} 1010 \mathrm{P}$ resist system. 


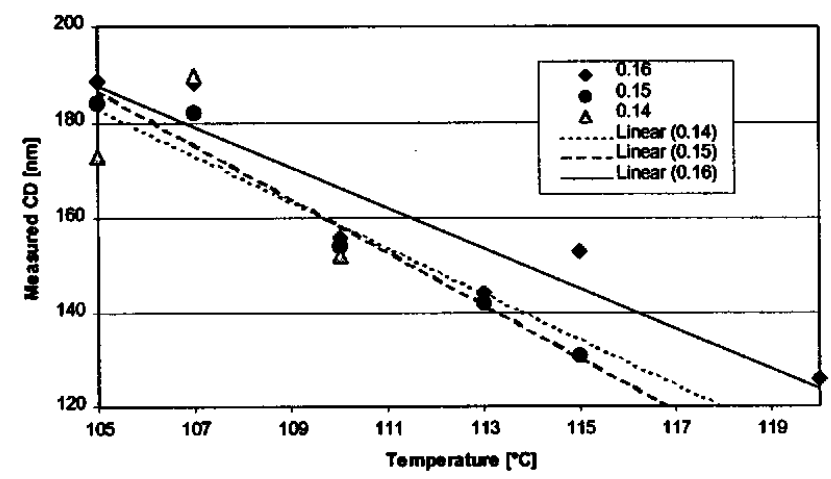

Fig. 10: Dependence of linewidth on PEB temperature for $A Z^{\circledR} E X P A X^{\mathrm{TM}} 1000 P$. The reduced $P E B$ dependence seen is a result of the lowered activation energy of deprotection.

As a result of the presence of beta substituents in 2-methyl-2-adamantanol and of the conjugation of the double bond and carbonyl group in the anhydromevalolactone cleavage product (cf. Scheme 1), the MAdMA/ MLMA resist system exhibits a lowered activation energy of the deprotection reaction. Fig. 10 shows the dependence of the linewidth of $A Z^{\circledR}$ EXP AX ${ }^{\mathrm{TM}} 1000 \mathrm{P}$ resist on PEB temperature for 140 to $160 \mathrm{~nm}$ features. Independent of the feature size, a slope of about $5 \mathrm{~nm} /{ }^{\circ} \mathrm{C}$ is observed, which is about half of what if seen for t-butyl leaving groups.

\subsection{Lithographic Properties of Cycloolefin Resist Systems}

Resist systems based on cycloolefin polymers are attractive because of the easy accessibility and potentially low cost of raw materials and because of their high etch resistance, particularly in fluorine plasma. ${ }^{4-6}$ Systems based on cycloolefin/maleic anhydride alternating copolymers are particularly attractive because they can be synthesized by standard free radical polymerization. One such system which has demonstrated high resolution and good adhesion on silicon is based on a tetrapolymer of butyl norbornecarboxylate (BNC), hydroxyethyl norbonenecarboxylate (HNC), norbornenecarboxylic acid (NC), and maleic anhydride. ${ }^{4}$

Resists based on the above polymer have been reported to resolve dense line features down to $130 \mathrm{~nm}$ with standard illumination. ${ }^{4}$ Figure 10 shows the performance for dense line features in a non-optimized resist formulation containing $\mathrm{BNC} / \mathrm{HNC} / \mathrm{NC} / \mathrm{MA}$ tetrapolymer. The resist was processed on B.A.R.C coated substrate using a film thickness of $451 \mathrm{~nm}$, a soft bake of $115^{\circ} \mathrm{C} / 60 \mathrm{sec}$, then exposed on the ISI $0.6 \mathrm{NA}$ ministepper at $\sigma=0.7$, baked at $110^{\circ} \mathrm{C} / 60 \mathrm{sec}$ and developed using $2.38 \mathrm{wt} \%$ aq. TMAH. In the present non-optimized form, the resist resolved $0.15 \mu \mathrm{m}$ dense lines with reasonable wall angle and film retention. The poly-silicon etch rate using $\mathrm{Cl}_{2} / \mathrm{HBr}$ etch chemistry of this resist is 1.35 times that of novolak resist as measured on a LAM 9400 etcher, and the resistance to fluorine etch chemistries has been reported as 1.00 for $\mathrm{CHF}_{3}$ and 1.07 for $\mathrm{SF}_{6}$ based etches. ${ }^{4}$ Further optimization work of this type of resist formulation is on-going, and the results will be reported elsewhere.

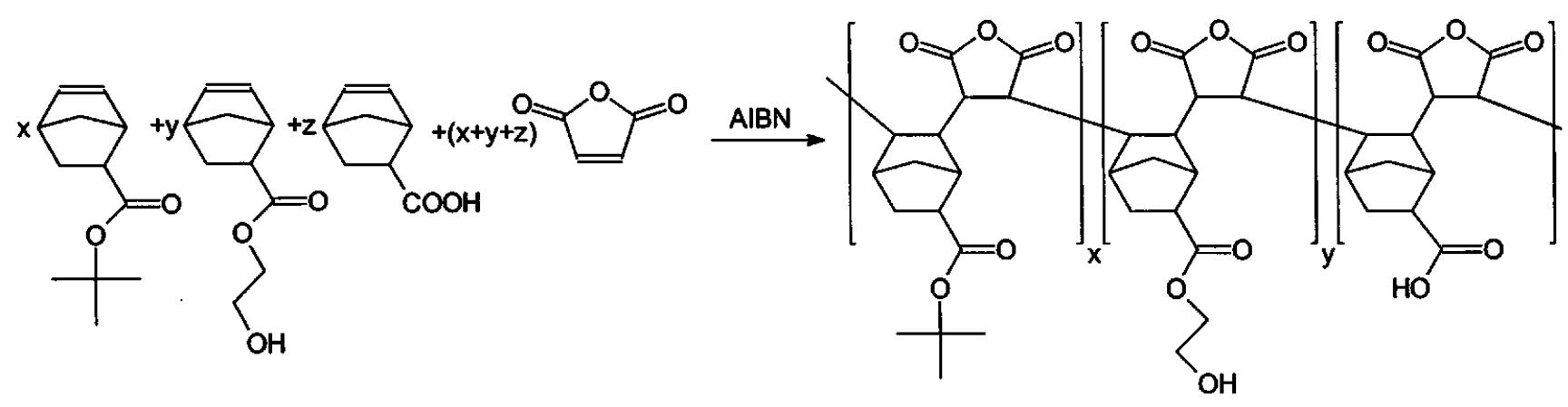

Scheme 2: Synthesis of BNC/HNC/NC/MA tetrapolymer 


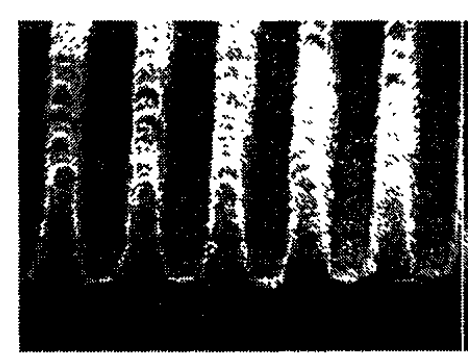

$0.14 \mu \mathrm{m} \mathrm{L/S}$

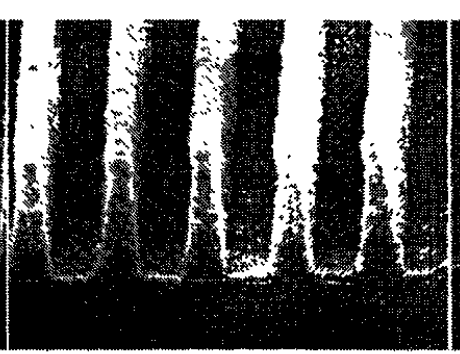

$0.15 \mu \mathrm{m} L / S$

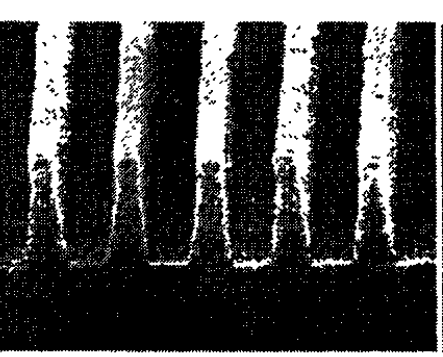

$0.16 \mu \mathrm{m} \mathrm{L} / \mathrm{S}$

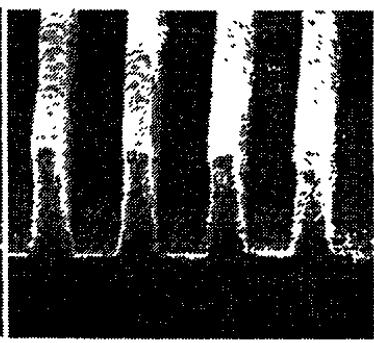

$0.17 \mu \mathrm{m} \mathrm{LS}$

Figure 11: Dense line performance of a non-optimized cycloolefin type resist based on $B N C / H N C / N C / M A$ tetrapolymer

\section{Performance Characterization of $193 \mathrm{~nm}$ Photoresists}

Photoresists for $193 \mathrm{~nm}$ lithography have come a long way in a relatively short time, and today's materials are capable of meeting the requirements for early production. However, it has already been shown by other studies ${ }^{8}$ that $193 \mathrm{~nm}$ resists still lag other chemically amplified systems in imaging performance. Our investigations confirm that this is the case: when imaged at $248 \mathrm{~nm}$, even the best current $193 \mathrm{~nm}$

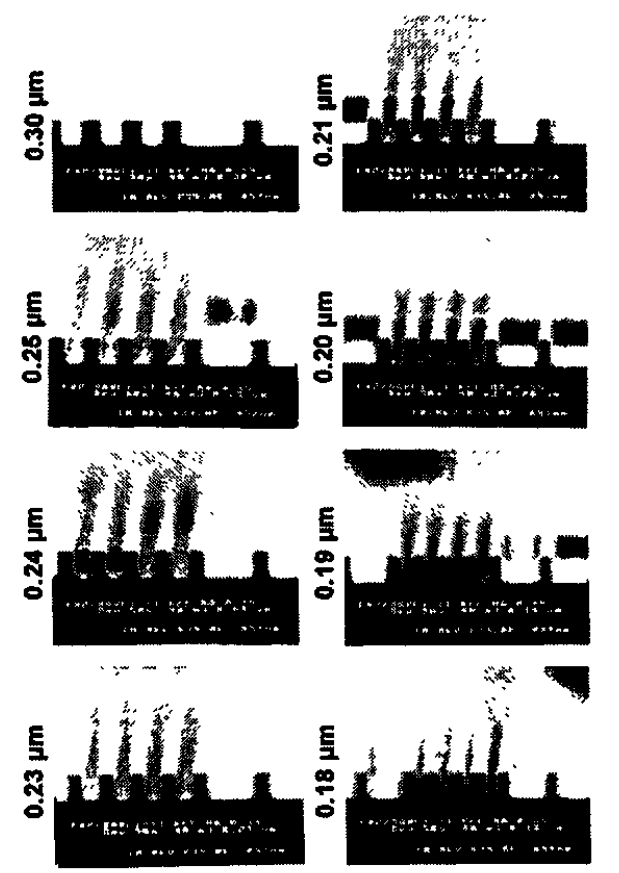

Fig. 12a: Performance of a modified $193 \mathrm{~nm}$ resist in $248 \mathrm{~nm}$ exposure ( $N A=0.55$, $\sigma=0.55$ ). resists, which resolve $130 \mathrm{~nm}$ dense features with $\mathrm{NA}=0.60$ and $\sigma=0.70$, fall short of the performance of state-of-the-art $248 \mathrm{~nm}$ resists.

For the $248 \mathrm{~nm}$ experiments, the $\mathrm{AZ}^{\circledR} \mathrm{EXP}$ $\mathrm{AX}^{\mathrm{TM}} 1000 \mathrm{P}$ formulation shown in Figs. 1-6 was modified by increasing the amount of PAG in order to arrive at a reasonable photospeed at 248 $\mathrm{nm}$ (Fig. 12a, $40 \mathrm{~mJ} / \mathrm{cm}^{2}$ ). This modification was necessary since the PAG absorption at 248 $\mathrm{nm}$ is much lower than that at $193 \mathrm{~nm}$. The modified formulation was imaged at $248 \mathrm{~nm}$
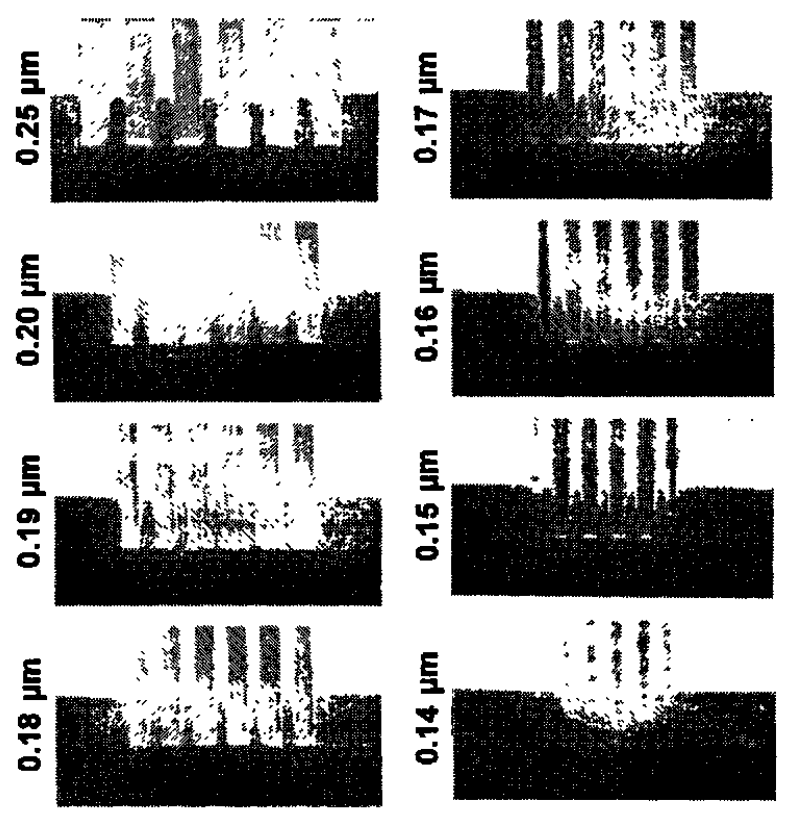

Fig. 12b: Performance of $A Z^{\circledR} E X P D X 2549$ $D U V$ resist with limiting resolution of $150 \mathrm{~nm}$ dense lines $(N A=0.55, \sigma=0.8)$ 
Normalized Image Log-Slope

$$
\begin{gathered}
N \mid L S=w \frac{\partial \ln I}{\partial x} \\
\text { w: feature size }
\end{gathered}
$$

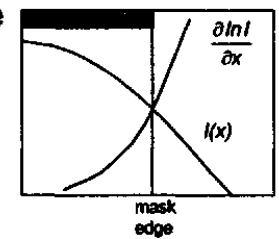

Fig. 13: Definition of the Normalized Image Log-Slope (NILS).

with a stepper set at $\mathrm{NA}=0.55$ and $\sigma=0.55$. The resulting images showed resolution down to about $190 \mathrm{~nm}$ dense lines (Fig. 12a). Under the same stepper settings, the most advanced 248 $\mathrm{nm}$ resists will show resolutions of down to 160 $170 \mathrm{~nm}$ dense lines under the same stepper settings. With higher NA and/or sigma values, dense line resolution of 150 or better are possible (Fig. 12b).

In order to be able to compare the resolving power of resists under different settings of the optical exposure tools, we have employed the normalized image log-slope (NILS) as a measure of the quality of the aerial image that the resist can still resolve. For line features, the NILS is defined as the product of the feature size times the derivative of the natural logarithm of the light intensity in the direction perpendicular to the line, evaluated at the mask edge (see Fig. 13).
The NILS is generally recognized as a good measure of the aerial image quality. ${ }^{9}$ In order to use it for resist performance evaluations, one has to determine what NILS value of the aerial image a resist can still resolve. The lower the NILS value the better the resist. A poor resist system might require a NILS of 3 or 4 to resolve the aerial image, while state-of-the-art resists can work with much lower NILS, as will be shown below.

Fig. $12 \mathrm{~b}$ shows the performance of the $\mathrm{AZ}^{\circledR} \mathrm{EXP}$ DX 2549 resist system on a stepper with $\mathrm{NA}=0.55$ and $\sigma=0.8$. Under these conditions, this resist shows a limiting resolution of $150 \mathrm{~nm}$ for dense line features. The $150 \mathrm{~nm}$ lines are only resolved in the center part of the 5-line dark field structure, i.e., the part that most closely corresponds to an infinite dense line array, which also is the area where aberrations such as coma will have the least impact. The calculation of the corresponding NILS value with the Prolith/2 simulator (Fig. 14) shows that for this sigma value, the resolution of $150 \mathrm{~nm}$ dense lines shows that the resist is capable of resolving aerial images with NILS values as low as about 0.7 .

In contrast, the performance of the modified $\mathrm{AZ}^{\circledR} \mathrm{EXP}$ AXTM1000P formulation at $248 \mathrm{~nm}$ corresponds to a NILS value of about 1.1 (Fig. 15). For purposes of comparison, it shall be

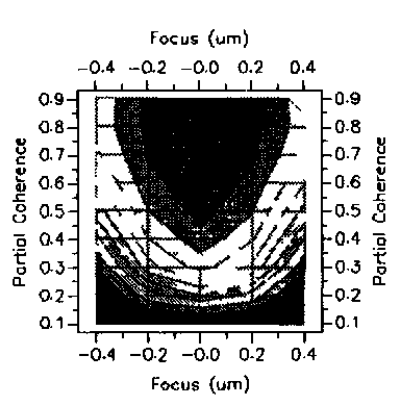

$200 \mathrm{~nm}$ dense lines

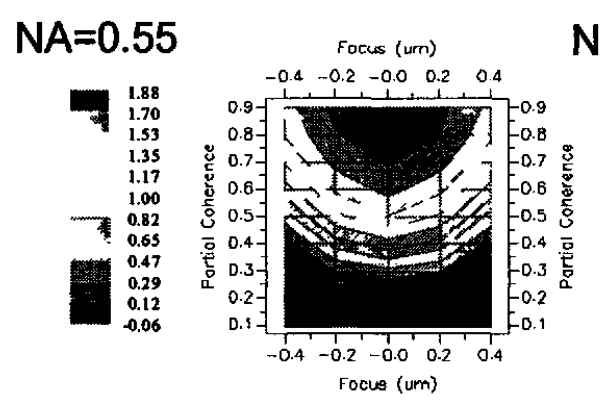

$180 \mathrm{~nm}$ dense lines

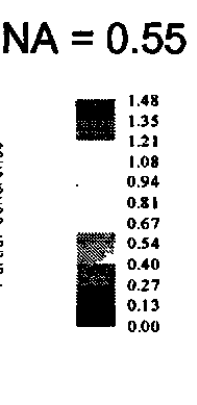

\begin{abstract}
.
Fig. 14: Contour diagrams of NILS values as a function of focus and partial coherence for 200, 180, and $150 \mathrm{~nm}$ dense lines (NA=0.55, $248 \mathrm{~nm}$ exposure wavelength).
\end{abstract}




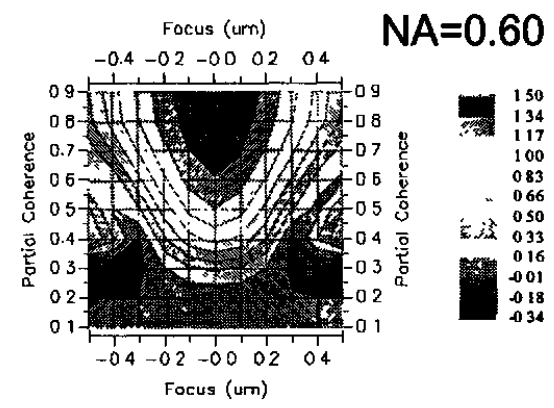

$130 \mathrm{~nm}$ dense lines

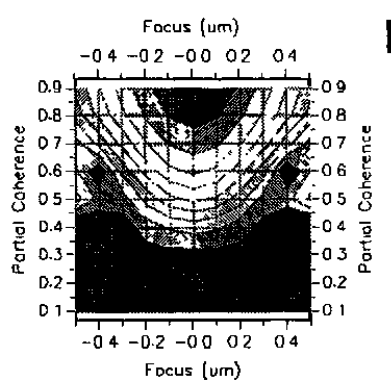

$120 \mathrm{~nm}$ dense lines
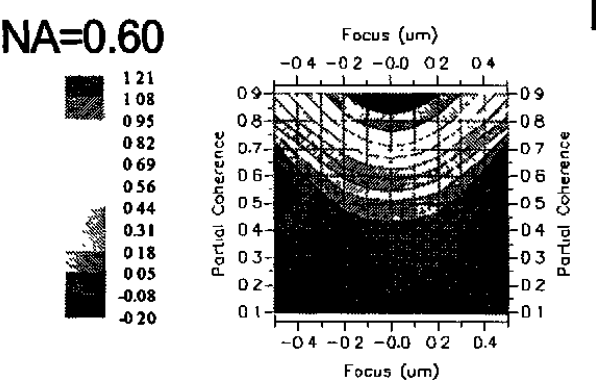

$110 \mathrm{~nm}$ dense lines

Fig. 15: Contour diagrams of NILS values as a function of focus and partial coherence for 130, 120 , and $110 \mathrm{~nm}$ dense lines (NA=0.60, $193 \mathrm{~nm}$ exposure wavelength).

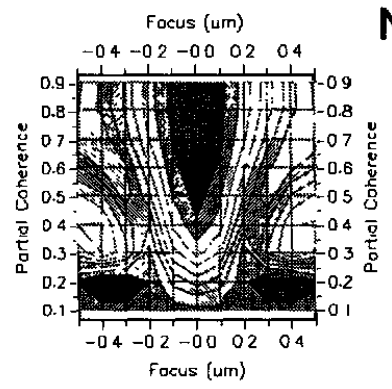

$120 \mathrm{~nm}$
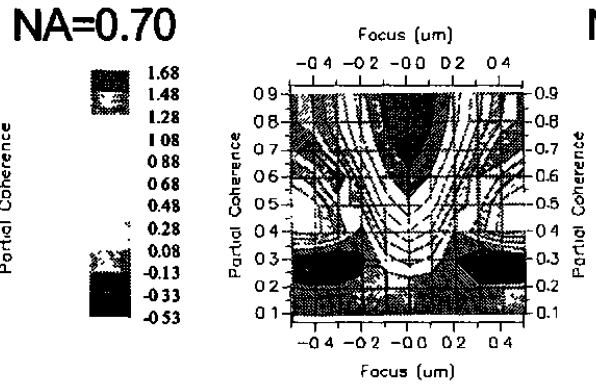

$110 \mathrm{~nm}$
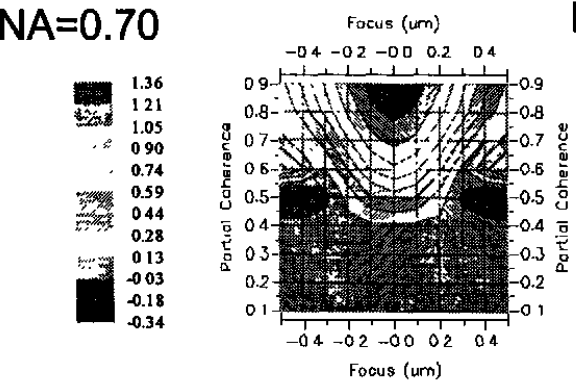

$\mathrm{NA}=0.70$

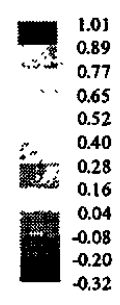

$100 \mathrm{~nm}$

Fig. 16: Contour diagrams of NILS values as a function of focus and partial coherence for 130, 120 , and $110 \mathrm{~nm}$ dense lines (NA=0.70,193 $\mathrm{nm}$ exposure wavelength).

pointed out that the performance of i-line resists, which have reached quarter-micron resolution after many decades of development, corresponds only to a NILS value of about 1.3 .

The above study of the NILS values ${ }^{10}$ thus leads to the conclusion that $248 \mathrm{~nm}$ DUV resists currently are the most advanced and most highly resolving resists available, with $193 \mathrm{~nm}$ resists still trailing in performance but already occupying a middle position between i-line and $248 \mathrm{~nm}$ systems. The use of chemical amplification has enabled the resist chemists to leapfrog the long period of development of iline resists in only a few years. The history of optical lithography has been one of life cycle extensions of existing technologies, pushing feature sizes into the deep sub-wavelength region. As it is to be anticipated that $193 \mathrm{~nm}$ lithography will suffer a similar fate at the hands of $248 \mathrm{~nm}$ lithography, it is important to know where the performance limits of $193 \mathrm{~nm}$ lithography will lie. The performance of $193 \mathrm{~nm}$ resists is one of the most important factors that will determine for which technology nodes 193 nm lithography can still be employed.

One way to approach this problem is to ask what performance one would expect at a wavelength of $193 \mathrm{~nm}$ if the resist performance were equal to the highest demonstrated one. In other words, what resolution performance would we see in $193 \mathrm{~nm}$ lithography if $193 \mathrm{~nm}$ resists would be as good as the best current $248 \mathrm{~nm}$ resists? While it is not clear whether such performance can be achieved within the constraints of $193 \mathrm{~nm}$ resist design (e.g., the need to work with carboxylic acid groups in 

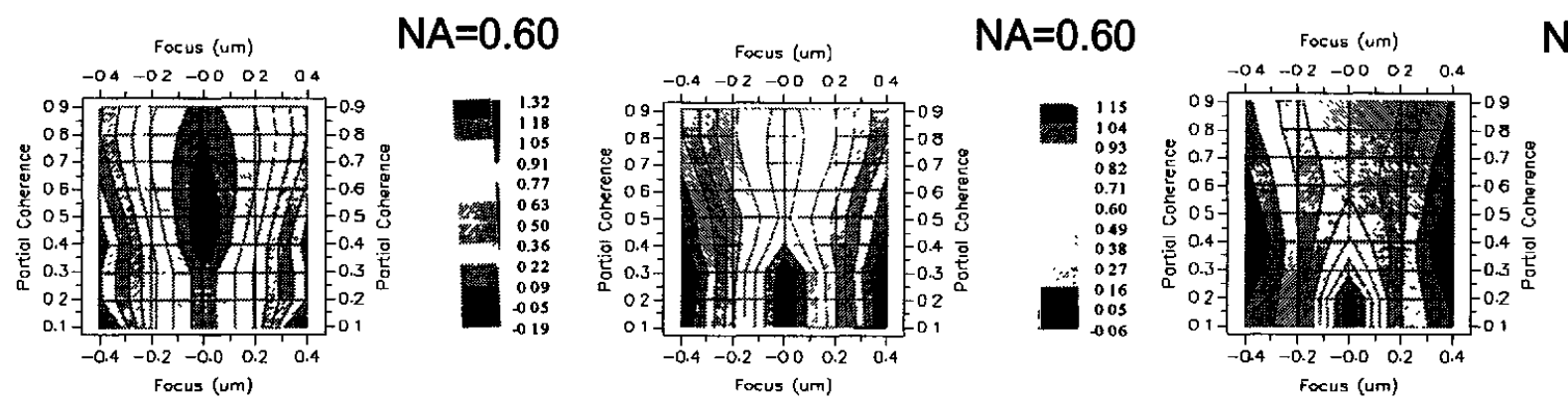

$\mathrm{NA}=0.60$

$110 \mathrm{~nm}$

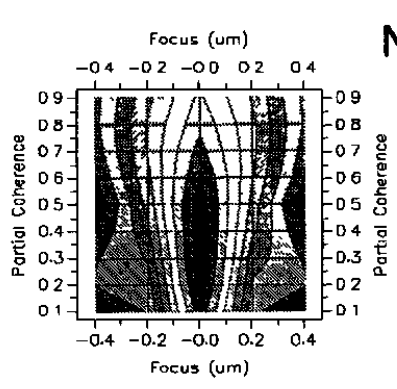

$110 \mathrm{~nm}$
$\mathrm{NA}=0.70$

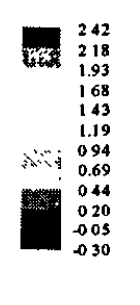

Fig. 17: Contour diagrams of NILS values as a function of focus and partial coherence for 110, 90, and $80 \mathrm{~nm}$ isolated lines ( $N A=0.60$ and $0.70,193 \mathrm{~nm}$ exposure wavelength).

standard strength developers), the historical precedent of $248 \mathrm{~nm}$ resist development would lend confidence to such an expectation.

Figs. 15 and 16 show calculated contour plots of the NILS for dense lines as a function of focus and partial coherence for a number of NA values and feature sizes (binary mask, no optical enhancements). From these diagrams, one can conclude what lithographic improvements could be realized if $193 \mathrm{~nm}$ resists were to become able to use a NILS value of 0.7. For a stepper with $\mathrm{NA}=0.60$ and $\sigma=0.70$, the resolution capability would be improved by only $10 \mathrm{~nm}$; however, the DOF for the $130 \mathrm{~nm}$ features would be increase to more than $0.7 \mu \mathrm{m}$. A partial coherence increase to 0.8 would make it possible to barely open the $100 \mathrm{~nm}$ lines. If one assumes that scanners with $\mathrm{NA}=0.70$ become available, the NILS $=0.7$ cutoff would move to the $100 \mathrm{~nm}$ dense line range (Fig. 16).
For isolated lines, the current $193 \mathrm{~nm}$ resist resolution is about $110 \mathrm{~nm}$ at $\mathrm{NA}=0.60$ and $\sigma=0.7$, which again corroborates a NILS limit of 1.1 (Fig. 17). If the required NILS were 0.7 , the isolated line resolution at this stepper setting would increase to $90 \mathrm{~nm}$, and to $80 \mathrm{~nm}$ if a stepper with $\mathrm{NA}=0.7$ was used. It should be noted that the optimum partial coherence for the isolated lines $(\sigma=0.5$ to 0.6$)$ is lower than for the dense lines.

\section{Conclusions}

Current $193 \mathrm{~nm}$ resists are capable of $130 \mathrm{~nm}$ resolution with binary masks and standard illumination on the first generation of exposure tools $(\mathrm{NA}=0.60)$. The 2-methyl-2-adamantane methacrylate/ mevalonic lactone methacrylatebased $\mathrm{AZ}^{\circledR}$ EXP $\mathrm{AX}^{\mathrm{TM}} 1000 \mathrm{P}$ resist shows good isolated and dense line performance, i.e., linear resolution down to $0.13 \mu \mathrm{m}$ with a binary and 
less than $0.10 \mu \mathrm{m}$ with a strong phase-shift mask. Contact hole performance is $150 \mathrm{~nm}$ with a binary mask. The resist is not annealed under the present processing conditions and consequently shows delay time issues. With the addition of a new additive related to AZ's 248 $\mathrm{nm}$ photobase technology, resists can be formulated for which the delay time in filtered environments exceeds one hour.

Calculation of the NILS values shows that if resist performance can be improved to the level currently exhibited by $248 \mathrm{~nm}$ resists (i.e., a required minimum NILS of 0.7 ), $120 \mathrm{~nm}$ dense and $90 \mathrm{~nm}$ isolated lines can be opened. If for future stepper systems, the NA is additionally increased to 0.7 , the resolution limit of $193 \mathrm{~nm}$ lithography without optical enhancements is predicted to lie at $100 \mathrm{~nm}$ dense lines and $80 \mathrm{~nm}$ isolated lines. However, a robust production process requires higher latitude than can be obtained at the final resolution of a resist. The $100 \mathrm{~nm}$ dense line technology node of the year $2004 / 2005$ will therefore have to use optical enhancements for $193 \mathrm{~nm}$ lithography, unless the performance of $193 \mathrm{~nm}$ resists can be pushed beyond that of today's $248 \mathrm{~nm}$ materials.

\section{Acknowledgements}

The authors would like to express their thanks to Jeff Meute, Ray Chang, Allen Stephen, Vicki Graffenberg, Georgia Rich and Shashi Patel of International SEMATECH for their help in the exposure experiments, to $\mathrm{G}$. Pawlowski and the AZ $248 \mathrm{~nm}$ research group for the images of Fig. 12, as well as to Patrick Paniez of France Telecom and his group for the MT/DSC studies.

\section{References}

(1) K. Nakano, S. Iwasa, K. Maeda, E. Hasegawa, Proc. SPIE 3333, 43 (1998).

(2) Y. Kaimoto, K. Nozaki, S. Takechi, and N. Abe, Proc. SPIE 1672, 66 (1992); S. Takechi, Y. Kaimoto, K. Nozaki, and N. Abe, J. Photopolym. Sci. Technol. 5 (3). 439 (1992).

(3) K. Nozaki, K. Watanabe, E. Yano, A. Kotachi, S. Takechi, and I. Hanyu, J. Photopolym. Sci. Tech. 9, 509-522 (1996); S Takechi, M. Takahashi, A. Kotachi, K. Nozaki, E. Yano, and I. Hanyu, J. Photopolym. Sci. Technol. 9 (3), 475-488 (1996); cf. also R.R. Dammel, S. Ficner, J. Oberlander, A. Klauck-Jacobs, M. Padmanaban, D.N. Khanna, and D.L. Durham, Proc. SPIE 3333, 144-151 (1998).

(4) J.C. Jung, C.K Bok, H. Baik, Proc. SPIE 3333 , 11 (1998); J.C. Jung, C.K. Bok, and K.H.Baik, J. Photopolym. Sci. Tech. 10, 529 (1997).

(5) M. Suwa, H. Iwasawa, T. Kajita, M. Yamamoto, and S.I. Iwanaga, Proc. SPIE 3333, 26 (1998)

(6) T. I. Wallow, P. J. Brock, R.A. Dipietro, R.D. Allen, J. Opitz, R. Sooriyakumaran, D. C. Hofer, J. Meute, J. D. Byers, G.K. Rich, M. McCallum, S. Schuetze, S. Jayaraman, K. Hullihen, R. Vicari, L. F. Rhodes, B. L. Goodall, and R. A. Shick, Proc. SPIE 3333, 92 (1998).

(7) P.J. Paniez, S. Gally, B. Mortini, C. Rosilio, P.O. Sassoulas, R. Dammel, M. Padmanaban, A. Klauck-Jacobs, and J. Oberlander, Proc. SPIE 3678, (1999), in print.

(8) J. Opitz, R.D. Allen, T.I. Wallow, G.M. Walraff, and D.C. Hofer, Proc. SPIE $\underline{3333}$, 571 (1998).

(9) C.A. Mack, "Inside Prolith" ${ }^{\text {TM", Finle }}$ Technologies, Austin, TX, 1998, p. 145ff, and literature quoted.

(10) All Prolith $/ 2$ calculations were carried out using a medium speed setting. Since some of the NAs studied were quite high, all calculations used the full vector model. 